\title{
Dimensionamento do quadro de funcionários das escolas de educação básica no Brasil ${ }^{1}$
}

\author{
Delimitation of the board staff in basic education schools in Brazil \\ Dimensionamiento del cuadro de funcionarios de educación básica en Brasil
}

\section{THIAGO ALVES \\ LÚCIA MARIA DE ASSIS \\ ALINE KAZUKO SONOBE \\ MARIANA MOSCHKOVICH ATHAYDE}

\begin{abstract}
Resumo: Este artigo apresenta lacunas nas políticas educacionais no que diz respeito aos funcionários de escola, reforçadas pela ausência de dados sobre esses profissionais no questionário específico do Censo da Educação Básica (CEB). Nesse sentido, propõe indicadores para dimensionamento do quadro de funcionários das escolas públicas, a partir do único item do CEB que permite obter informações sobre esses profissionais: "Total de funcionários da escola (inclusive profissionais escolares em sala de aula)". Os resultados, por escola, mostram grande variabilidade, tendo em vista a heterogeneidade do sistema, e sugerem que novos estudos explicativos são necessários para compreender melhor essas diferenças.
\end{abstract}

Palavras-chave: Funcionários de escola; Profissionais da educação; Indicadores educacionais; Valorização dos profissionais da educação; Educação Básica.

Abstract: This article presents gaps in educational policies about school staff, reinforced by the lack of data about these professionals in the specific questionnaire of the Basic Education Census (CEB). In this sense, it proposes indicators for the sizing of the public-school staff, based on the only CEB item that allows obtaining information from these professionals: In this sense, it proposes indicators for the sizing of the public-school staff, based on the only CEB item that allows obtaining information from these professionals: "Total school staff (including school staff in the classroom)". The results show great variability in the results per school, considering the heterogeneity of the system, and suggest that new explanatory studies are necessary to better understand these differences.

Keywords: school staff; education professionals; educational indicators; appreciation of education professionals; basic education.

1 Artigo elaborado no âmbito do Laboratório de Dados Educacionais (www.dadoseducacionais.c3sl. ufpr.br) e do projeto de pesquisa "Simulador de Custo-Aluno Qualidade" (www.simcaq.c3sl.ufpr.br) financiado pela SASE/MEC. 
Resumen: Este artículo presenta lagunas en las políticas educativas en cuanto a los funcionarios de escuela, reforzadas por la ausencia de datos sobre estos profesionales en el cuestionario específico del Censo de la Educación Básica (CEB). En este sentido, propone indicadores para dimensionamiento del cuadro de funcionarios de las escuelas públicas a partir del único ítem del CEB que permite obtener informaciones de esos profesionales: "Total de funcionarios de la escuela (inclusive profesionales escolares en clase)". Los resultados muestran una gran variabilidad en los resultados por escuela, teniendo en cuenta la heterogeneidad del sistema y sugieren que nuevos estudios explicativos son necesarios para comprender mejor estas diferencias.

Palabras-chave: funcionarios escolares; profesionales de la educación; indicadores educativos; valorización de los profesionales de la educación; educación básica.

\section{INTRODUÇÃO}

Os profissionais que atuam em funções de apoio e complementação das ações de ensino-aprendizagem estão presentes nas escolas públicas de Educação Básica desde o estabelecimento das primeiras escolas no Brasil, com os Jesuítas, a partir de 1550, em Salvador, na Bahia, com o início do funcionamento do "Colégio dos Meninos de Jesus"2. Com a expulsão dos jesuítas do Brasil e início da Reforma Pombalina (1772-1834), instituíram-se as “aulas régias”, que funcionavam em salas de prédios públicos, sacristias de Igrejas ou nas casas dos próprios professores. Nesses espaços, quem cuidava dos aspectos materiais e de apoio eram os escravos domésticos. Os espaços escolares só voltaram à cena no Brasil na segunda metade do século XIX, "quando algumas províncias do Império resolveram construir sedes próprias para os liceus, [...] e passaram a contar com funcionários, muitos recrutados entre escravos libertos". (MONLEVADE, 2009, p. 341).

Já no século XX, palco de grandes transformações sociais que repercutiram no papel da escola, esses trabalhadores seguem invisibilizados e desvalorizados como profissionais da educação, se comparados ao protagonismo dos docentes e discentes no âmbito das políticas públicas. Essa invisibilidade é, portanto, histórica, conforme explica Monlevade (2009):

2 De acordo com Monlevade (2009, p. 340), entre os Jesuítas, os clérigos que cuidavam da infraestrutura material dos colégios eram denominados "irmãos coadjutores", cujas funções abrangiam desde os projetos arquitetônicos dos colégios e intérpretes de línguas indígenas até funções como de bibliotecários, escriturários, inspetores de disciplina, repetidores de lições e mestres de primeiras letras. 
[Entre os Jesuítas] havia uma identidade do coadjutor, colada à identidade do jesuíta educador, mesmo que ele fosse vaqueiro, horticultor ou piloto de navio. Já no período subsequente, a associação mental que se fazia dos outros que trabalhavam nas escolas era com os escravos. A invisibilidade era reforçada pelo "não-valor": por mais importante que fosse o seu papel [...] Mas a ordem escravocrata também ruiu, chegaram os imigrantes e, com eles, o assalariamento. Cresceram as cidades, adveio a República. Dali em diante não haverá mais "escravos escolares", mas o caráter de subalternidade dos funcionários perdurou no século XX e Brasil adentro. (MONLEVADE, 2009, p. 342).

Nos dias de hoje, segunda década do século XXI, essa invisibilidade e falta de valorização ainda não foi superada e reflete na indefinição de suas funções, no quantitativo de pessoas que devem compor o quadro de funcionários em cada escola, na ausência de oportunidades de formação, de planos de carreira e de remuneração condigna em muitas redes públicas. Essa invisibilidade também é percebida no pequeno número de pesquisas e publicações sobre funcionários, quando comparado aos estudos sobre professores. Sobre esse aspecto, verificouse que a Confederação Nacional dos Trabalhadores em Educação (CNTE) tem incentivado a realização e publicação de grande parte das pesquisas sobre o tema no Brasil $1^{3}$.

Das pesquisas que tratam sobre o tema, observa-se um constante resgate das conquistas legislativas que, a partir de 2003, tratam de dois eixos principais: o reconhecimento e a formação desses trabalhadores. Destacam-se como reconhecimento, as emendas e alterações que incluíram os funcionários de escola nos textos das leis, que antes tratavam apenas de 'profissionais do ensino' e 'profissionais do magistério' e passaram a tratar de 'profissionais da educação', como a Emenda Constitucional nº 53/2006 (BRASIL, 2006) e Lei no 12.014/2009 (BRASIL, 2009).

Igualmente, determinou-se a realização de censo específico para a categoria, conforme o Plano Nacional da Educação - PNE 2014-2024 (BRASIL, 2014). No eixo formação, destacam-se a oferta de cursos técnico-profissionais com base na Resolução CNE/CEB no 5/2005 (BRASIL, 2005) e a definição de diretrizes curriculares nacionais para formação em nível superior, pela Resolução CNE/CES nº 2/2016 (BRASIL, 2016b). Outro eixo de análise está relacionado à remuneração dos funcionários no contexto do financiamento da educação em

3 O periódico "Retratos da Escola", iniciativa da Escola de Formação da CNTE, publicou volumes especiais sobre o tema dos profissionais da educação, incluindo os funcionários: "Funcionário de Escola: identidade e profissionalização" (CNTE, 2009), "Condições de Trabalho e Saúde dos Profissionais em Educação" (CNTE, 2012) e "Valorização Profissional: piso salarial e carreira" (CNTE, 2016a). Também publicou artigos tratando do tema ao abordar questões como formação e valorização profissional em outros volumes (ASSIS, 2017; SILVA, 2014; VIEIRA, 2014). O tema também é abordado em diversos volumes da publicação "Cadernos de Educação" e em publicações especiais, como a cartilha "Funcionários da educação: conquistas e desafios da formação e da valorização profissional” (CNTE, 2016b). 
condições de qualidade. Conforme propõem Carreira e Pinto (2007), a previsão de um quadro de funcionários para cada escola com quantidade de profissionais por função e o respectivo valor de remuneração é um dos itens que compõem a matriz de cálculo do Custo-Aluno-Qualidade Inicial (CAQi). Esse aspecto ganha relevo no debate atual, uma vez que a implantação do CAQi e do CAQ são estratégias previstas na meta 20 do referido PNE.

Contudo, ainda que haja avanços, percebe-se que a categoria segue em segundo plano quando ações que deveriam abarcar todos os profissionais da educação são realizadas apenas para profissionais docentes (ASSIS, 2017). Duas importantes evidências nesse sentido são: 1) o estabelecimento do Piso Salarial Profissional Nacional (PSPN) por meio da Lei 11.738/2008 (BRASIL, 2008), que contemplou apenas a remuneração dos professores com formação em nível médio; e 2) a ausência de coleta de dados sobre as características dos funcionários das escolas em questionário específico do Censo da Educação Básica, realizado anualmente pelo Instituto Nacional de Pesquisas Educacionais Anísio Teixeira (INEP), assim como é feito com os professores ${ }^{4}$, o que pode ter contribuído para reforçar essa desvalorização. Atualmente, esse levantamento coleta somente o número total de funcionários de cada unidade escolar, incluindo os docentes. Isso permite apenas estimar, por diferença, o número total de funcionários que não atuam em sala de aula, o que se obtém subtraindo-se, do número total de profissionais da escola, o número total de profissionais que atuam em sala de aula. Esse caso apresenta informações muito agregadas que não permitem a identificação das funções exercidas pelos funcionários, bem como seu nível de formação e tipo de vínculo contratual, por exemplo. Portanto, os dados disponíveis não são suficientes para subsidiar (i) análises de dimensionamento do quadro de funcionários, o que permitiria saber o número de funcionários existentes nas escolas brasileiras e o quanto seria necessário, (ii) estimativas do impacto da remuneração desses profissionais no financiamento da educação e (iii) elaboração de políticas públicas de valorização profissional, como a implantação de cursos específicos direcionados à formação inicial, definição das condições de trabalho e valorização da carreira.

Neste trabalho, compreende-se como funcionários de escola, ou simplesmente 'funcionários', os trabalhadores indicados no inciso III, do Art. 61 da Lei de Diretrizes e Bases da Educação Nacional (LDB) - Lei 9.394/1996 (BRASIL, 1996), que trata de "trabalhadores em educação, portadores de diploma

\footnotetext{
4

O Censo da Educação Básica (CEB) é realizado anualmente pelo Instituto Nacional de Estudos e Pesquisas Educacionais Anísio Teixeira (INEP), em regime de colaboração com as secretarias de educação e participação das instituições de ensino públicas e privadas. O CEB tem como unidades de análise os estabelecimentos de ensino, turmas, matrículas e profissionais da educação que atuam em sala de aula.
} 
de curso técnico ou superior em área pedagógica ou afim". Ainda, entendemse como funcionários de escola também os que atuam nas áreas de Secretaria Escolar, Alimentação Escolar, Infraestrutura Escolar, Multimeios Didáticos, Biblioteconomia e Orientação Comunitária e outras, previstas pelo Decreto $\mathrm{n}^{\circ}$ 8.752/2016 (BRASIL, 2016) mas que ainda não portam o diploma. Todavia, devido aos limites dos dados coletados pelo Censo da Educação Básica, os resultados apresentados neste estudo são relativos aos 'profissionais que atuam fora da sala de aula; portanto, contempla apenas os trabalhadores que atuam em unidades escolares. Desse modo, inclui, além da categoria dos funcionários delimitada acima, outros profissionais da educação definidos no Art. 61 da LDB que atuam em funções tradicionalmente ocupadas por profissionais com formação para atuar também na docência, dentre as quais a gestão e a coordenação pedagógica.

Ante o exposto, este artigo pretende tratar dos desafios gerados pela ausência de dados relativos aos funcionários no Censo da Educação Básica. Nesse sentido, propõe indicadores para dimensionamento do quadro de funcionários das escolas públicas de Educação Básica e, especificamente, apura a quantidade de funcionários em cada escola, de modo a compreender a composição desse quantitativo em relação ao número de matrículas, de professores, de turmas e de salas de aulas. A fonte de dados utilizada foram os microdados do Censo da Educação Básica de 2016, disponibilizados no sítio eletrônico do INEP.

A partir desse ponto, o artigo está estruturado em quatro seções: uma breve revisão da literatura; procedimentos metodológicos; resultados e discussão; e considerações finais.

\section{UMA BREVE REVISÃO DA LITERATURA SOBRE OS FUNCIONÁRIOS DE ESCOLA}

A superação da invisibilidade dos funcionários de escola no Brasil tem início com o autorreconhecimento desses profissionais enquanto categoria, expresso por sua organização sindical, iniciada na década de 1980. Em 1990, articulam-se com a Confederação dos Professores do Brasil (CPB) e unificam suas lutas na Confederação Nacional dos Trabalhadores em Educação (CNTE). No entanto, de acordo com Monlevade (2014, p. 81):

Serem recepcionados na lei como profissionais - desde que devidamente habilitados em cursos técnicos e tecnológicos - e admitidos em conselhos escolares ou até mesmo elegíveis para funções de direção de escolas, são avanços inimagináveis, meio século atrás. Mas nem por isso os funcionários da educação deixaram de ser politicamente subalternos. Basta estar presente às reuniões de colegiados para perceber que seus votos nas decisões se alinham com os dos gestores ou com os dos docentes, numa suave subordinação, que mostra o seu pouquíssimo poder. 
O não entendimento dos funcionários como educadores e as indefinições das funções que devem realizar na escola reforçam a subvalorização, que vem acompanhada de baixos salários e falta de planos de carreira. Ainda, quando os planos existem, percebe-se uma construção de hierarquias entre as funções desempenhadas pelos funcionários que, com funções mais próximas da docência, como secretarias e bibliotecárias, por exemplo, são mais valorizados em detrimento das funções de limpeza e conservação (MONLEVADE, 2014, p. 84).

O reconhecimento passa a incidir na legislação brasileira a partir de 2005, com o estabelecimento da Proposta de Diretrizes Curriculares Nacionais para a área profissional dos Serviços de Apoio Escolar pelo Conselho Nacional de Educação (CNE), no Parecer CNE/CEB 16/2005 (BRASIL, 2005b) e na instituição da área de Serviços de Apoio Escolar, como a 21a Área Profissional, através da Resolução CNE/CEB no 5/2005. (BRASIL, 2005a)

Em 2006, promulga-se a Emenda Constitucional no 53 (BRASIL, 2006) que, entre outras questões, altera a nomenclatura de profissionais do ensino para profissionais da educação e estabelece o Fundo de Manutenção e Desenvolvimento da Educação Básica e de Valorização dos Profissionais da Educação (Fundeb). A Lei 11.494/2007 (BRASIL, 2007), que regulamenta o Fundeb, por sua vez, estabelece que (Art. 40):

\footnotetext{
Os Estados, o Distrito Federal e os Municípios deverão implantar Planos de Carreira e remuneração dos profissionais da educação básica, de modo a assegurar: [...] I - a remuneração condigna dos profissionais na educação básica da rede pública; [...] II - integração entre o trabalho individual e a proposta pedagógica da escola; [...] III - a melhoria da qualidade do ensino e da aprendizagem.
}

No entanto, de acordo com Assis (2017), os funcionários seguem tratados como coadjuvantes na educação escolar, uma vez que não contemplaram a categoria em tela a Lei ${ }^{\circ} 11.738 / 2008$ (BRASIL, 2008), que institui o piso para os profissionais do magistério; o Decreto no 6.755/2009, que institui a Política Nacional de Formação de Profissionais do Magistério da Educação Básica; e a Resolução CNE/CEB no 2/2009 (BRASIL, 2009b), que fixa diretrizes nacionais para planos de carreira e remuneração de profissionais do magistério.

Em agosto de 2009, inicia-se um período de maior reconhecimento legal dos funcionários de escola, a partir da Lei no 12.014/ 2009 (BRASIL, 2009b), que inclui na LDB a categoria III de profissionais da educação como "trabalhadores em educação, portadores de diploma de curso técnico ou superior em área pedagógica ou afim”. Para Assis (2017), esta inclusão passa a garantir a 
formação da categoria e reforça a necessidade do estabelecimento de uma política de formação em nível superior que contemple as especificidades das funções exercidas por esses profissionais ${ }^{5}$.

Até então, as funções dos funcionários são exercidas por profissionais oriundos das mais diversas áreas de formação, com o predomínio de diplomados em área pedagógica, o que demonstra a relação das atividades dos funcionários de escola com os processos educativos. As leis, decretos e resoluções que regulamentam a área desde a Lei 12.014/2009 (BRASIL, 2009a) passaram a se referir aos "profissionais da educação" e não mais "profissionais do magistério", incluindo os funcionários de escola em seus textos, seja com determinações gerais, nas quais também se consideram os docentes, seja quanto às questões específicas da categoria.

O Plano Nacional da Educação (PNE 2014-2024), Lei no 13.005/2014 (BRASIL, 2014), trata de profissionais da educação em diversos momentos ao longo de seu texto. No entanto, Assis (2015) propõe uma análise mais detalhada dos contextos das metas e estratégias que utilizam essa denominação, destacando as que se referem aos profissionais do magistério, tendo as estratégias que utilizam diretamente a denominação funcionários a real intenção de valorizar essa categoria específica. Ainda assim, o PNE 2014-2024 apresenta avanços no que diz respeito à valorização dos funcionários de escola. Por outro lado, a falta de efetivação das estratégias reduz o impacto do plano na visibilização da categoria.

O direcionamento das políticas de valorização dos funcionários de escola passa pela necessidade de conhecimento das características da categoria, como faixa etária, gênero, escolaridade, dados funcionais etc., permitindo, por exemplo, a identificação real das demandas de formação (ASSIS, 2015), o que poderá auxiliar na elaboração de política voltada a esses profissionais. Nesse sentido, observa-se a estratégia 18.5, da Meta 18 do PNE 2014-2024, que determina a realização anual do "censo dos (as) profissionais da Educação Básica de outros segmentos que não os do magistério" a partir do segundo ano de vigência do plano, ainda não realizada. Em diagnóstico realizado para o Conselho Nacional de Educação, Assis (2015) indica a inclusão dos dados sobre funcionários de escola no Censo da Educação Básica como demanda importante para fundamentar as

5 A este respeito o CNE em parceria com a UNESCO contratou consultoria especializada para o “desenvolvimento de estudos sobre as políticas de formação do profissional da Educação Básica no âmbito da Educação Superior, sob os marcos legais vigentes, incluindo o PNE, Lei 13.005/2014, com vistas a subsidiar a proposição de Diretrizes Curriculares Nacionais - DCN para a formação desses profissionais em nível superior”. O texto apresenta um "diagnóstico das iniciativas de formação inicial, em nível superior, e formação continuada dos profissionais da Educação Básica (FTA) efetivadas pelas IES, especialmente as Universidades Públicas e Institutos Federais"(ASSIS, 2015). Disponível em: <http://portal.mec.gov.br/index.php?option=com docman\&view $=$ download $\&$ alias $=26091$-diagnostico-iniciativas - formacao-inicial-continuada-profissionaisedfisica-basica-pdf\&Itemid=301>. Acesso em: 27/05/2018. 
políticas de formação de funcionários. Devido à ausência de coleta sistemática sobre os funcionários no Censo da Educação Básica, em 2009, a CNTE realizou um levantamento a partir de questionário enviado a entidades sindicais estaduais para traçar o perfil dos funcionários sindicalizados de escola (DOURADO; MORAES, 2009). As perguntas se referiam à caracterização dos funcionários, incluindo a dimensão profissional e a caracterização das entidades sindicais, além de questões sobre relacionamento funcionário-sindicato e visão sobre políticas estaduais para a categoria. Das 27 entidades contatadas, 24 responderam, tendo sido observado que, em $29,17 \%$ dos casos, a resposta se deu a partir de uma comissão estabelecida pelo sindicato e, em outros 70,83\% dos casos, uma única pessoa ficou responsável.

Em relação ao quantitativo apurado de funcionários escolares sindicalizados, $70,83 \%$ dos respondentes se referiram a dados aproximados, devido à falta de sistematização. Dourado e Moraes (2009) consideram que essa informação reforça a necessidade de inclusão dos dados sobre funcionários no censo educacional. A pesquisa apurou o total de 124.949 funcionários de escola sindicalizados, sendo $28,06 \%$ do sexo masculino e $71,94 \%$ do sexo feminino. Em comparação com o total de profissionais da educação que eram sindicalizados (390.205), o número de funcionários representava 32,06\%. Sobre as questões profissionais, identificou-se que 54,7\% tinham contratação em regime estatutário, e que $58,33 \%$ indicaram o provimento ao cargo a partir de concurso público.

É importante destacar que a diversidade de nomenclaturas para os cargos e as funções dificultou a análise das respostas referentes à remuneração, assim como a informação sobre exigências de formação. O programa federal Profuncionário ${ }^{6}$ teve destaque nas respostas sobre as ações formativas, apresentando compreensão de impacto positivo na carreira.

Dourado e Moraes (2009) concluem que é necessário estabelecer indicadores para análise dessa categoria profissional que incluam, além do censo, o cadastramento sindical e a sistematização de pesquisas que permitam a construção de séries históricas, além de consolidar a formação destes profissionais em nível superior e a definir um piso salarial.

\footnotetext{
6 O Programa de Formação Inicial em Serviço dos Profissionais da Educação Básica dos Sistemas de Ensino Público (Profuncionário) foi instituído pelo Decreto n ${ }^{\circ} 7.415 / 2010$ (BRASIL, 2010), com o objetivo de promover, preferencialmente por meio da educação a distância, formação técnica em nível médio para servidores atuantes na Educação Básica pública, com implementação feita em regime de colaboração entre os entes federados. Este decreto foi revogado pelo Decreto n ${ }^{\circ}$ 8.752/2016 (BRASIL, 2016), que dispõe sobre a Política Nacional de Formação dos Profissionais da Educação Básica, incluindo todos os trabalhadores da educação, e prevendo cursos técnicos e superiores para os funcionários de escola.
} 


\section{DEFINIÇÃO DOS ASPECTOS METODOLÓGICOS DO ESTUDO}

Esta seção apresenta os procedimentos metodológicos que tornaram possível apurar o número de 'profissionais que atuavam fora da sala de aula' no ano de 2016. Os resultados consideraram somente as escolas públicas estaduais e municipais, por entender que os desafios relacionados aos funcionários estão situados majoritariamente nessas redes, que, em 2016, atendiam $80,8 \%$ das 48,8 milhões de matrículas da Educação Básica do país e 99\% das 39,8 milhões de matrículas ofertadas pelas escolas públicas.

A fonte de dados quantitativos desse estudo é o Censo da Educação Básica de 2016. É importante ressaltar que o INEP alterou a forma de coleta dos dados desse levantamento a partir de 2007 e o formato atual da coleta dados se dá por meio de cadastros/formulários eletrônicos individuais por 'escola' pública e privada e para cada 'turma', 'matrícula' e 'função docente' dessas escolas, disponíveis no sistema EducaCenso. Essa forma de coleta gera bancos de dados com inúmeras variáveis descritoras das características de cada uma das quatro unidades de análise citadas. Assim, por ser uma forma mais desagregada de disseminação dos dados de um levantamento ${ }^{7}$, os microdados desses bancos de dados permitem análises muito detalhadas e inúmeros cruzamentos das variáveis contidas em cada banco de dados, uma vez que é possível relacionar as informações entre os bancos por meio do código único atribuído às escolas, turmas, matrículas e professores. Por exemplo, é possível analisar as características das turmas e dos alunos do Ensino Médio para os quais os professores licenciados em física dão aula. Também é possível saber, por exemplo, qual o perfil de professores, de turmas e de escolas destinados às crianças negras atendidas na pré-escola em estabelecimentos públicos urbanos das capitais brasileiras.

Infelizmente, as mesmas possibilidades de análises não são aplicáveis aos funcionários de escola, uma vez que não há um cadastro específico para esses profissionais. Para ilustrar a diferença do tratamento dispensado pelo Censo da Educação Básica aos funcionários em relação aos professores e alunos, em 2016,

\footnotetext{
$7 \quad$ Outras formas de disseminação de dados, inclusive adotadas pelo INEP, são as 'sinopses estatísticas' (http://portal.inep.gov.br/web/guest/sinopses-estatisticas) e as plataformas de consultas (metadados) como, por exemplo, o "Painel Educacional” (http://portal.inep.gov.br/web/guest/painel-educacional). Todavia, por mais aperfeiçoadas que sejam essas formas de disseminação agregadas, elas sempre apresentarão limitações quanto ao número de perguntas que elas podem responder.
} 
o cadastro de "aluno" coletou 30 itens de informações específicas de cada criança, jovem ou adulto matriculado. $\mathrm{O}$ instrumento de "profissional escolar em sala de aula" coletou 29 itens contendo informações específicas ${ }^{8}$.

Desse modo, para alunos e profissionais, em grande medida, é possível traçar um quadro com características sociodemográficas e da atuação profissional para subsidiar as políticas e a gestão destinada a esses atores em cada rede pública e privada do país. Para os funcionários, o Censo continuou a estratégia de coleta anterior a 2007, pois a única informação que se tem sobre os funcionários em todo o levantamento no ano de 2016 está na seção "Recursos Humanos" do questionário da escola, item 39, que solicitou a seguinte informação: "Total de funcionários da escola (inclusive profissionais escolares em sala de aula)". Ou seja, a única variável relativa aos funcionários trata apenas do quantitativo totalizado de profissionais que atuam dentro e fora de sala de aula. Por isso, nesse estudo, foi possível apurar apenas o número de "profissionais que atuam fora da sala de aula”, conforme mostra a fórmula constante na ilustração 1 (adiante).

\section{ELABORAÇÃO DE INDICADORES}

Os limites da fonte de dados utilizada fazem com que as estratégias metodológicas empregadas neste artigo se dividam em duas partes. A primeira é voltada à apuração do número de funcionários em cada escola, ou seja, visa a responder à seguinte questão: "quantos funcionários há em cada unidade escolar"? A segunda parte volta-se para a elaboração de indicadores que permitem dimensionar o número de funcionários das escolas em relação ao número de matrículas, professores, salas de aulas e turmas. Esses são indicadores do tipo razão. A partir da análise dos indicadores gerados, espera-se fornecer subsídios para compreender como se dá o dimensionamento do quadro de funcionários nas escolas públicas.

O número de funcionários por escola é um indicador simples, unidimensional, e do tipo 'contagem'. O cálculo desse indicador poderia ser trivial se o Censo da Educação Básica coletasse os dados dos funcionários de modo individualizado, do mesmo modo que é feito com os professores. Da forma como é realizada, faz-se necessário explicar as escolhas realizadas na aplicação de filtros necessários para a subtração do número de profissionais que atuam em sala de

8 Para os dados de alunos, cada criança, adolescente, jovem e adulto tem um código único do INEP (equivalente a um CPF). O mesmo se aplica aos profissionais em sala de aula. Mas se um aluno tiver mais de uma matrícula, ele terá questionário específico para cada matrícula de modo a assegurar a coleta dos dados específicos de cada matrícula (escola e turma). Novamente, a mesma lógica é aplicada aos professores. O número de questionários é correspondente ao número de turmas que atuam. Ou seja, para professores coletam-se os dados no nível de função docente. 
aula para, em seguida, calcular o número de funcionários por diferença. Vários resultados são possíveis, a partir das escolhas realizadas. Por isso, neste estudo, o indicador "número de funcionários" foi calculado a partir da aplicação da fórmula indicada na ilustração 1.

\section{Ilustração 1 - Fórmula de cálculo do indicador "Número de funcionários"}

\begin{tabular}{|c|c|}
\hline [1] Número de funcionários = [Total de funcionários da escola] - [Total de profissionais que atuam em sala de aula] \\
\hline $\begin{array}{c}\text { Onde: } \\
\text { Número de funcionários: }\end{array}$ & expressa o número de profissionais que atuam fora da sala de aula \\
\hline Total de funcionários da escola: & $\begin{array}{c}\text { somatório do número informado pela escola no item "Total de } \\
\text { funcionários da escola (inclusive profissionais escolares em sala } \\
\text { de aula)" }\end{array}$ \\
\hline Total de Profissionais em sala de aula: & $\begin{array}{c}\text { somatório do número de profissionais que atuam em sala de aula. } \\
\text { Considera todos as categorias da variável "TP_TIPO_DOCENTE" } \\
\text { (Função que exerce na escola) e as categorias da variável } \\
\text { "TP_TIPO_TURMA" (Tipo de atendimento) }\end{array}$ \\
\hline
\end{tabular}

Fonte: Elaboração dos autores

Outros quatro indicadores foram calculados (vide fórmulas na ilustração 2. Nos indicadores do tipo razão, o número de sujeitos ou objetos que no conjunto das escolas públicas brasileiras há em maior número foi colocado no 'numerador'. Por exemplo, há mais matrículas do que funcionários nas escolas brasileiras (isso fica evidente na tabela 2 , inserida na próxima seção). Logo, o indicador é a "razão matrículas por funcionário". Isso é menos óbvio para a relação entre funcionários fora de sala de aula e profissionais do magistério. Também utilizando a apuração realizada para elaboração da tabela 2 , optou-se pela "razão profissionais em sala por funcionário".

Esses quatro indicadores visam a elucidar o dimensionamento do quadro de funcionários em relação ao tamanho da oferta de ensino (número de matrículas e turmas), ao porte do prédio de escolas (número de salas existentes) e aos profissionais do magistério, cujo tamanho do quadro é conhecido.

Esses indicadores estão na mesma direção do que propõe o indicador "Número de matrículas por professor", que é amplamente utilizado para analisar o esforço docente nas escolas. Em relação aos funcionários, para cada escola foi calculado: (fórmula 2) o número de profissionais atuantes em sala de aulas para cada funcionário; (fórmula 3) número de matrículas ofertadas para cada funcionário; (fórmula 4) número de funcionários lotados na escola para cada turma; e (fórmula 5) número de funcionários para cada sala existente no prédio escolar. Vide ilustração 2. 


\section{Ilustração 2 - Fórmulas de cálculo dos indicadores de dimensionamento do quadro de funcionários}

\begin{tabular}{|c|c|}
\hline \multicolumn{2}{|c|}{$\begin{array}{l}\text { [2] Razão "profissionais em sala" por "funcionários" = [número de profissionais que atuam em sala de } \\
\text { aula] / [número de funcionários] }\end{array}$} \\
\hline $\begin{array}{l}\text { Onde: } \\
\text { Número de profissionais que atuam em sala de aula: }\end{array}$ & $\begin{array}{c}\text { somatório do número de profissionais que atuam em } \\
\text { sala de aula. } \\
\text { Considera todos as categorias da variável "TP_TIPO_ } \\
\text { DOCENTE") } \\
\text { (Função que exerce na escola) e as categorias da } \\
\text { variável } \\
\text { TP_TIPO_TURMA" (Tipo de atendimento) }\end{array}$ \\
\hline Número de funcionários: & $\begin{array}{l}\text { expressa o número de profissionais que atuam fora da } \\
\text { sala de aula (vide fórmula 1) }\end{array}$ \\
\hline \multicolumn{2}{|c|}{ [3] Razão "matrículas" por "funcionários" = [número de matrículas presenciais] / [número de funcionários] } \\
\hline $\begin{array}{l}\text { Onde: } \\
\text { Número de matrículas presenciais: }\end{array}$ & $\begin{array}{c}\text { número de matrículas TP_TIPO_TURMA (Tipo de } \\
\text { atendimento) }=0,1,2 \text { e } 3 ; \text { e } \\
\text { TP_MEDIACAO_DIDATICO_PEDAGO = } 1\end{array}$ \\
\hline Número de funcionários: & $\begin{array}{c}\text { expressa o número de profissionais que atuam fora da } \\
\text { sala de aula (vide fórmula 1) }\end{array}$ \\
\hline \multicolumn{2}{|c|}{ [4] Razão "funcionários" por "turma" = [número de funcionários] / [número de turmas] } \\
\hline $\begin{array}{l}\text { Onde: } \\
\text { Número de funcionários: }\end{array}$ & $\begin{array}{c}\text { expressa o número de profissionais que atuam fora da } \\
\text { sala de aula (vide fórmula 1) }\end{array}$ \\
\hline Número de turmas: & número de turmas existentes na escola. \\
\hline \multicolumn{2}{|c|}{ [5] Razão "funcionários" por "sala de aula" = [número de funcionários] / [número de sala de aula] } \\
\hline $\begin{array}{l}\text { Onde: } \\
\text { Número de funcionários: }\end{array}$ & $\begin{array}{l}\text { expressa o número de profissionais que atuam fora da } \\
\text { sala de aula (vide fórmula 1) }\end{array}$ \\
\hline Número de salas de aula: & número de salas de aula existentes no prédio escolar \\
\hline
\end{tabular}

Fonte: Elaboração dos autores

\section{ANÁLISE DOS RESULTADOS OBTIDOS}

Esta seção apresenta os resultados auferidos a partir da aplicação das fórmulas mencionadas aos dados de 145.378 escolas públicas constantes no CEB 2016, sendo 114.719 municipais e 30.659 estaduais9. A tabela 1 apresenta uma análise descritiva geral dos resultados.

9

As 687 escolas federais que ofertam matrículas na Educação Básica não foram consideradas nessa análise por apresentarem perfis muito diversos das demais escolas públicas. Uma parte dessas escolas são institutos federais que, em geral, informam o número de funcionários de todo o instituto, ainda que as matrículas de ensino médio sejam apenas uma pequena parcela da oferta de ensino. Isso gera distorções significativas nos resultados. 


\section{Tabela 1 - Medidas descritivas dos indicadores de dimensionamento do quadro de profissionais da educação básica, escolas estaduais e municipais, Brasil, 2016.}

\begin{tabular}{|c|c|c|c|c|c|c|c|}
\hline Medidas descritivas & $\begin{array}{l}\text { Profissionais } \\
\text { da Educação }\end{array}$ & $\begin{array}{c}\text { Profissionais } \\
\text { em sala de } \\
\text { aula }\end{array}$ & Funcionários & $\begin{array}{c}\text { Razão } \\
\text { profissionais } \\
\text { em sala/ } \\
\text { funcionários }\end{array}$ & $\begin{array}{c}\text { Razão } \\
\text { matriculas/ } \\
\text { funcionários }\end{array}$ & $\begin{array}{c}\text { Razão } \\
\text { funcionários/ } \\
\text { turma }\end{array}$ & $\begin{array}{c}\text { Razão } \\
\text { funcionários/ } \\
\text { sala }\end{array}$ \\
\hline Número de escolas & 145.378 & 145.378 & 145.378 & 136.634 & 136.301 & 145.378 & 145.378 \\
\hline Total de profissionais & 4.400 .978 & 2.455 .415 & 1.945 .563 & & & & \\
\hline Média & 30,3 & 16,9 & 13,4 & 1,7 & 24,0 & 1,3 & 2,1 \\
\hline Desvio-padrão & 45,9 & 16,2 & 39,1 & 2,3 & 33,9 & 6,4 & 9,7 \\
\hline Coeficiente de Variação & $152 \%$ & $96 \%$ & $292 \%$ & $132 \%$ & $141 \%$ & $492 \%$ & $470 \%$ \\
\hline $10 \%$ menores & 3,0 & 1,0 & 1,0 & 0,5 & 7,0 & 0,3 & 0,5 \\
\hline 10 quartil & 8,0 & 4,0 & 3,0 & 0,9 & 11,0 & 0,7 & 1,0 \\
\hline Mediana & 23,0 & 13,0 & 9,0 & 1,2 & 17,4 & 1,0 & 1,7 \\
\hline 30 quartil & 43,0 & 24,0 & 18,0 & 2,0 & 27,0 & 1,6 & 2,5 \\
\hline $90 \%$ maiores & 66,0 & 39,0 & 30,0 & 3,0 & 41,9 & 2,2 & 3,6 \\
\hline
\end{tabular}

Fonte: Elaborado a partir dos microdados do Censo da Educação Básica 2016

O resultado da aplicação da fórmula 1 indica que a existência de 1.945 .563 funcionários (que, de acordo com as possibilidades da fonte de dados, deve ser interpretada como 'profissionais que atuam fora de sala de aula'). Na tabela 1, esse número pode ser calculado subtraindo-se o número total de profissionais em sala de aula (2.455.415) do total de profissionais das escolas (4.400.978). Em média, há 13,4 funcionários por escola. Todavia, há grande dispersão no número de cada escola, o que pode ser explicado pelo porte da escola e tipo de etapa/modalidade de ensino ofertado. Essa variabilidade está expressa na tabela pelos altos valores do desvio-padrão e coeficiente de variação.

As medidas de posição ajudam a compreender o tamanho do quadro de funcionários no universo das escolas analisadas. Calculando o $10^{\circ}$ percentual, verificou-se que $10 \%$ das escolas (cerca de 14.450) têm no máximo um funcionário. $\mathrm{Na}$ verdade, uma análise de frequência dessa variável revelou que cerca de $6 \%$ do total das escolas analisadas $(\mathrm{n}=8.750)$ não têm funcionários. $\mathrm{O} 1^{\circ}$ quartil revela que $25 \%$ das escolas com menor número de funcionários têm até três profissionais atuando fora das salas de aula. Apesar de 13,4 funcionários por escola corresponder à média, o número de funcionários tem uma distribuição muito assimétrica positivamente. Observa-se que há muitas escolas com pequeno número de funcionários e poucas escolas com grande número de funcionários. A mediana mostra que $50 \%$ das escolas contam com até nove funcionários. 
As escolas com maior número de funcionários têm pelo menos 18 profissionais fora de sala de aula ( $3^{\circ}$ quartil). As $10 \%$ com maior quantidade tem pelo menos 30 funcionários. É razoável supor que a localização das escolas, se no campo ou na cidade, pode ser uma variável explicativa para o número de funcionários de cada escola. Uma análise semelhante à apresentada na tabela 2 confirma essa hipótese. Por uma questão de espaço, não serão apresentadas essas tabelas, mas, nas 62.302 escolas do campo, o número médio de funcionários é igual a 5,4. 25\% dessas escolas têm apenas um funcionário; $50 \%$ têm apenas três funcionários; $25 \%$ das escolas com maior quantidade de funcionários têm pelo menos sete funcionários. Em geral, 10\% das escolas possuem pelo menos 13 funcionários). Nas 83.706 escolas urbanas, esses números são significativamente maiores: 19,4 em média, 25\% menores com até cinco funcionários, $50 \%$ com até 15 funcionários; e as $25 \%$ com maiores com pelo menos 25 funcionários. Esses resultados evidenciam a heterogeneidade das escolas públicas brasileiras também quanto ao quantitativo de funcionários.

Analisando os indicadores do tipo razão constantes na tabela 1 , as medidas descritivas permitem análises semelhantes. Quanto à razão professores por funcionários, em geral, há mais profissionais do magistério que profissionais em funções fora de sala de aula. A média igual a 1,7 indica que uma escola com 10 funcionários possui 17 professores. Esse indicador também é muito disperso. O $1^{\circ}$ quartil indica que em $25 \%$ das escolas essa razão é 0,9 , ou seja, há mais funcionários que profissionais em sala de aula. Em 50\% das escolas (mediana), a razão é de até 1,2 . Somente em $25 \%$ das escolas, a razão é igual ou maior que dois, ou seja, há pelo menos dois profissionais do magistério para cada funcionário em cada escola.

A razão 'número de matrículas por funcionário' permite ter uma noção de quantos funcionários são lotados nas escolas a partir do tamanho da oferta educacional de cada estabelecimento. Essa razão é particularmente importante para as discussões do CAQi/CAQ, uma vez que a relação entre número de matrículas e funcionários implica ganho ou perda de escala (em uma noção econômica), e isso implica considerável aumento ou redução do custo por aluno, conforme mostram os trabalhos de Carreira e Pinto, 2007 e Alves, 2012. Em média, há 24 matrículas por funcionário nas escolas analisadas. Em 10\% das escolas, essa relação é de sete matrículas por funcionário. Metade das escolas tem até 17,4 matrículas por funcionário. Em $25 \%$ das escolas essa razão é de pelo menos 27.

A razão número de funcionários por turma segue a mesma lógica de tentar encontrar parâmetros para análise da demanda de funcionários. O número de turmas tem a vantagem de captar, em alguma medida, o número de turnos que 
funciona na escola. Isso, em geral, é levado em conta pelas secretarias de educação ao autorizarem o número de funcionários que pode ser lotado nas escolas. A tabela 1 mostra que os números desse indicador são baixos. Metade das escolas tem razão igual a um, ou seja, metade das escolas têm no máximo um funcionário para cada turma existente nas escolas, sendo que grande parte das escolas têm mais funcionários que turmas (vide $1^{\circ}$ quartil).

A razão do número de funcionários por sala de aula existente apresentase de moderada a alta correlação positiva com o indicador número de funcionários por turma ( $\mathrm{r}$ de Pearson $=0,61)$, o que guarda alguma coerência. Entretanto, a razão funcionários por sala visa a analisar o aspecto do tamanho do prédio escolar na análise. Por essa medida, em média, há 2,7 funcionários para cada sala de aula existente nas escolas públicas brasileiras. Em 75\% das escolas há pelo menos um funcionário para cada sala existente (vide $1^{\circ}$ quartil). Em metade das escolas, a relação não chega a dois funcionários para cada sala (mediana igual a 1,7).

A tabela 2 apresenta os números de escolas, matrículas, profissionais em sala de aula e funcionários por Unidade da Federação (UF), considerando redes estaduais e municipais, conjuntamente. Ela permite analisar como os 1,94 milhão de funcionários se distribuem pelos estados, considerando-se as variáveis potencialmente explicativas. Para compreender a relação entre os números de cada variável no cenário nacional, verificou-se que há fortíssima correlação positiva entre número de escolas de cada UF com o número de funcionários ( $\mathrm{r}$ de Pearson = 0,946), número de matrículas x funcionários ( $\mathrm{r}$ de Pearson $=0,996)$ e número de profissionais do magistério x funcionários ( $\mathrm{r}$ de Pearson = 0,987). Ou seja, em geral, há coerência entre os números: quanto maior é o número de matrículas nos estados, maior é o número de funcionários e o aumento tem uma tendência linear e proporcional.

A última coluna da tabela 2 apresenta a razão entre a quantidade de profissionais que atuam em sala de aula em relação aos que atuam fora de sala em cada UF. A razão em nível nacional é 1,26, ou seja, para cada 10 funcionários, têmse quase 13 professores. Porém, em 10 estados, a razão é superior à nacional (SC, PR, PI, RS, AM, MS, SP, ES, RJ, MA). Esse grupo é composto majoritariamente por estados do Sul e Sudeste, com exceção de MG, mas há pelo menos um estado das demais regiões. Em SC, a proporção é de dois profissionais em sala para cada funcionário. De acordo com a tabela 2, somente em seis estados há mais funcionários do que profissionais em sala de aula (PE, RO, RN, DF, RR e TO). Em RR, DF e TO, a razão é inferior a 0,90. Cabe comentar que RR também é um estado com o menor número de matrículas por funcionários $(12,8)$, o que é coerente em termos de dimensionamento de funcionários. 
Tabela 2 - Número de escolas, matrículas e profissionais em sala de aula e funcionários por UF, escolas estaduais e municipais, Brasil, 2016

\begin{tabular}{|c|c|c|c|c|c|c|}
\hline Região & UF & Escolas & Matrículas & $\begin{array}{l}\text { Profissionais } \\
\text { em sala de aula }\end{array}$ & Funcionários & $\begin{array}{c}\text { Razão } \\
\text { profissionais em } \\
\text { sala/ funcionários }{ }^{1}\end{array}$ \\
\hline \multirow{8}{*}{ Norte } & RO & 1.130 & 386.348 & 18.823 & 20.632 & 0,91 \\
\hline & $A C$ & 1.590 & 253.063 & 14.098 & 11.788 & 1,20 \\
\hline & $\mathrm{AM}$ & 5.117 & 1.060 .425 & 57.450 & 37.331 & 1,54 \\
\hline & RR & 758 & 130.818 & 8.940 & 10.254 & 0,87 \\
\hline & PA & 10.192 & 2.105 .561 & 104.561 & 93.629 & 1,12 \\
\hline & AP & 762 & 203.805 & 12.518 & 12.206 & 1,03 \\
\hline & To & 1.474 & 360.490 & 20.096 & 23.486 & 0,86 \\
\hline & Região & 21.023 & 4.500 .510 & 236.486 & 209.326 & 1,13 \\
\hline \multirow{10}{*}{ Nordeste } & MA & 11.496 & 1.783 .173 & 118.535 & 92.676 & 1,28 \\
\hline & PI & 4.659 & 809.988 & 56.197 & 35.433 & 1,59 \\
\hline & CE & 6.322 & 1.706 .607 & 100.611 & 90.988 & 1,11 \\
\hline & $\mathrm{RN}$ & 2.939 & 651.973 & 37.903 & 42.362 & 0,89 \\
\hline & PB & 4.434 & 799.256 & 50.420 & 48.396 & 1,04 \\
\hline & PE & 6.834 & 1.717 .608 & 84.404 & 85.708 & 0,98 \\
\hline & AL & 2.554 & 723.693 & 36.521 & 34.722 & 1,05 \\
\hline & SE & 1.808 & 423.355 & 23.314 & 20.277 & 1,15 \\
\hline & BA & 15.621 & 3.019 .479 & 171.264 & 167.961 & 1,02 \\
\hline & Região & 56.667 & 11.635 .132 & 679.169 & 618.523 & 1,10 \\
\hline \multirow{5}{*}{ Sudeste } & MG & 12.325 & 3.797 .031 & 257.267 & 217.553 & 1,18 \\
\hline & ES & 2.840 & 766.235 & 54.344 & 41.784 & 1,30 \\
\hline & $R J$ & 6.456 & 2.405 .557 & 167.887 & 130.344 & 1,29 \\
\hline & SP & 18.079 & 7.746 .354 & 465.276 & 333.882 & 1,39 \\
\hline & Região & 39.700 & 14.715 .177 & 944.774 & 723.563 & 1,31 \\
\hline \multirow{4}{*}{ Sul } & PR & 7.272 & 2.110 .387 & 169.569 & 99.216 & 1,71 \\
\hline & $\mathrm{SC}$ & 5.180 & 1.258 .466 & 103.025 & 50.598 & 2,04 \\
\hline & RS & 7.443 & 1.886 .070 & 144.130 & 93.081 & 1,55 \\
\hline & Região & 19.895 & 5.254 .923 & 416.724 & 242.895 & 1,72 \\
\hline \multirow{5}{*}{ Centro-Oeste } & MS & 1.286 & 588.348 & 43.433 & 29.054 & 1,49 \\
\hline & MT & 2.281 & 739.197 & 47.269 & 38.105 & 1,24 \\
\hline & GO & 3.474 & 1.137 .693 & 64.514 & 57.715 & 1,12 \\
\hline & DF & 639 & 455.057 & 23.046 & 26.382 & 0,87 \\
\hline & Região & 7.680 & 2.920 .295 & 178.262 & 151.256 & 1,18 \\
\hline & BRASIL & 144.965 & 39.026 .037 & 2.455 .415 & 1.945 .563 & 1,26 \\
\hline
\end{tabular}

Fonte: Elaborado a partir dos microdados do Censo da Educação Básica 2016

Nota: (1) Número de profissionais que atuam em sala de aula $\div$ número de funcionários

A tabela 3 apresenta informações das 26 redes estaduais, da rede do Distrito Federal e de 26 redes municipais das capitais. Esses números permitem uma análise de 53 redes públicas expressivas do ponto de vista da quantidade 
de matrículas de Educação Básica ofertada no país, pois, em conjunto, ofertam $50,1 \%$ das matrículas presenciais (19,5 milhões); mantém 26,5\% das escolas $(38,4$ mil) e $43,8 \%$ dos funcionários (852 mil) das escolas estaduais e municipais do país.

Tabela 3 - Número de escolas, funcionários e quartis do número de funcionários nas escolas por UF, escolas estaduais e municipais das capitais, Brasil, 2016

\begin{tabular}{|c|c|c|c|c|c|c|c|c|c|c|c|}
\hline \multirow{3}{*}{ Região } & \multirow{3}{*}{$\mathrm{UF}$} & \multicolumn{5}{|c|}{ Rede Estadual } & \multicolumn{5}{|c|}{ Rede Municipal da capital } \\
\hline & & \multirow{2}{*}{$\begin{array}{c}\text { Escolas } \\
\text { (N) }\end{array}$} & \multirow{2}{*}{\begin{tabular}{|c|} 
Funcionários \\
(N)
\end{tabular}} & \multicolumn{3}{|c|}{ Quartil } & \multirow{2}{*}{$\begin{array}{c}\text { Escolas } \\
(\mathrm{N})\end{array}$} & \multirow{2}{*}{\begin{tabular}{|c|} 
Funcionários \\
(N)
\end{tabular}} & \multicolumn{3}{|c|}{ Quartil } \\
\hline & & & & 10 & 20 & 30 & & & lo & 20 & 30 \\
\hline \multirow{7}{*}{ Norte } & RO & 420 & 10.608 & 1 & 25 & 39 & 138 & 1.960 & 5 & 11 & 21 \\
\hline & $\mathrm{AC}$ & 613 & 6.314 & - & 1 & 16 & 81 & 1.589 & 11 & 20 & 25 \\
\hline & $\mathrm{AM}$ & 738 & 16.698 & 9 & 16 & 29 & 488 & 3.047 & 3 & 5 & 8 \\
\hline & RR & 381 & 6.252 & - & 3 & 21 & 109 & 1.807 & 6 & 16 & 25 \\
\hline & PA & 856 & 17.353 & 9 & 17 & 27 & 151 & 2.956 & 8 & 13 & 26 \\
\hline & AP & 392 & 8.312 & 3 & 10 & 34 & 79 & 1.288 & 7 & 15 & 25 \\
\hline & TO & 513 & 10.277 & 13 & 19 & 26 & 72 & 1.987 & 19 & 24 & 32 \\
\hline \multirow{9}{*}{ Nordeste } & MA & 1.104 & 14.746 & - & 4 & 20 & 194 & 3.558 & 9 & 14 & 23 \\
\hline & PI & 661 & 9.521 & 6 & 11 & 20 & 300 & 6.823 & 10 & 16 & 27 \\
\hline & CE & 710 & 16.451 & 15 & 22 & 27 & 287 & 7.810 & 18 & 26 & 34 \\
\hline & $\mathrm{RN}$ & 607 & 15.589 & 10 & 17 & 26 & 146 & 3.554 & 15 & 21 & 30 \\
\hline & PB & 733 & 15.750 & 13 & 19 & 28 & 176 & 5.372 & 16 & 27 & 44 \\
\hline & PE & 1.057 & 22.901 & 11 & 19 & 28 & 308 & 9.043 & 19 & 25 & 39 \\
\hline & AL & 306 & 7.537 & 14 & 21 & 31 & 131 & 2.690 & 13 & 17 & 25 \\
\hline & SE & 354 & 6.877 & 12 & 18 & 26 & 73 & 1.347 & 10 & 13 & 19 \\
\hline & BA & 1.282 & 36.232 & 13 & 21 & 34 & 419 & 8.562 & 15 & 19 & 24 \\
\hline \multirow{4}{*}{ Sudeste } & MG & 3.643 & 98.500 & 14 & 23 & 33 & 317 & 7.509 & 15 & 21 & 30 \\
\hline & ES & 481 & 10.772 & 10 & 22 & 32 & 101 & 3.994 & 31 & 38 & 50 \\
\hline & RJ & 1.324 & 30.219 & 9 & 18 & 30 & 1.491 & 24.761 & 9 & 15 & 21 \\
\hline & SP & 5.717 & 139.213 & 13 & 21 & 32 & 1.493 & 45.954 & 21 & 27 & 37 \\
\hline \multirow{3}{*}{ Sul } & PR & 2.144 & 41.797 & 10 & 17 & 26 & 390 & 10.410 & 7 & 16 & 40 \\
\hline & $\mathrm{SC}$ & 1.254 & 14.476 & 4 & 9 & 15 & 116 & 1.908 & 11 & 15 & 21 \\
\hline & RS & 2.557 & 42.396 & 6 & 12 & 18 & 98 & 2.786 & 15 & 25 & 39 \\
\hline \multirow{4}{*}{$\begin{array}{l}\text { Centra- } \\
\text { Oeste }\end{array}$} & MS & 362 & 11.634 & 19 & 27 & 37 & 194 & 4.714 & 11 & 16 & 34 \\
\hline & MT & 764 & 21.105 & 18 & 26 & 35 & 158 & 3.247 & 3 & 21 & 31 \\
\hline & GO & 1.047 & 17.154 & 12 & 15 & 19 & 302 & 8.300 & 17 & 25 & 36 \\
\hline & DF & 639 & 26.382 & 27 & 37 & 48 & & & & & \\
\hline \multicolumn{2}{|c|}{ BRASIL } & 30.659 & 675.066 & & & & 7.812 & 176.976 & & & \\
\hline
\end{tabular}

Fonte: Elaborado a partir dos microdados do Censo da Educação Básica 2016.

Os dados da tabela 3 mostram que há correlação entre o número de escolas e funcionários das redes analisadas ( $\mathrm{r}$ de Pearson de 0,97 para redes estaduais e 0,92 para redes municipais). Todavia, também revela que o quantitativo de funcionários nas escolas de cada rede é bastante heterogêneo. A explicação dessa variabilidade requeria uma análise dos portes das escolas de cada rede, pois é razoável supor que escolas maiores requerem mais funcionários. 


\section{CONSIDERAÇÕES FINAIS}

O esforço para o dimensionamento do quadro de funcionários das escolas públicas de Educação Básica parte da compreensão de que esse é um aspecto importante para dar visibilidade aos trabalhadores que atuam em funções de apoio e complementação das ações de ensino-aprendizagem e que são, portanto, atores fundamentais para a garantia do direito à educação de qualidade para os alunos e alunas nas escolas brasileiras. Nesse sentido, saber o tamanho do quadro de profissionais é decisivo para dimensionar os esforços de formação e valorização dos profissionais.

A parte de valorização, no que se refere à remuneração, é aspectochave para a previsão de recursos necessários para financiar adequadamente as escolas, num cenário de discussão permanente do Fundeb e de estratégias para viabilizar a implementação do CAQi/CAQ como valores de referência para os mecanismos de financiamento. Mas, tão necessário quanto discutir os valores para uma remuneração adequada dos funcionários, é dimensionar adequadamente o número de funcionários de cada rede do país, uma vez que não há documentos orientadores ou normativos que estabeleçam padrões para a composição do quadro de funcionários, com previsão de funções e o quantitativo para cada função de acordo com o perfil das escolas quanto ao seu porte, contexto de atuação e etapas/modalidades ofertadas, dentre outros aspectos a considerar. Nesse sentido, os indicadores que estabelecem relações entre a quantidade de funcionários das escolas e o número de matrículas, professores, turmas e salas de aulas existentes é uma tentativa de compreender a realidade das escolas públicas.

Novos estudos são necessários para identificar padrões a partir dos cinco indicadores propostos nesse estudo. Igualmente relevante é a realização de uma pesquisa documental para identificar e analisar a legislação que orienta a lotação de funcionários no âmbito das redes estaduais e municipais. Isso ajudaria a compreender como são constituídos os quadros de funcionários das escolas e permitiria o confronto entre as orientações propostas e o quantitativo existente nas escolas.

Finalmente, é importante frisar que os indicadores aqui propostos têm limitações devido à forma agregada de coleta de dados relativos aos funcionários no CEB. Por isso, é fundamental que o INEP cumpra a estratégia 18.5, da Meta 18 do PNE 2014-2024, que determina "realizar anualmente, a partir do segundo ano de vigência deste PNE, por iniciativa do Ministério da Educação, em regime de colaboração, o censo dos (as) profissionais da educação básica de outros segmentos que não os do magistério" (BRASIL, 2014). 


\section{REFERÊNCIAS}

ALVES, T. Desenvolvimento de um modelo de previsão de custos para planejamento de sistemas públicos de educação básica em condições de qualidade: uma aplicação a municípios de Goiás. Tese. 2012. 353f. Tese (Doutorado em Administração) - Universidade de São Paulo, São Paulo. 2012.

ASSIS, L. M. Desenvolvimento, aprimoramento e consolidação de educação de qualidade. CNE/UNESCO, 2015. Documento técnico.

Disponível em: $\quad<$ http://portal.mec.gov.br/index.php?option=com_ docman\&view $=$ download $\&$ alias $=26091$-diagnostico-iniciativas-formacao-inicialcontinuada-profissionais-edfisica-basica-pdf\&Itemid=30192>. Acessado em: 14/04/2018.

ASSIS, L. M. Funcionários administrativos - Um balanço crítico da EB. Revista Retratos da Escola, Brasília, v. 11, n. 21, p. 641-661, jul.-dez., 2017.

BRASIL. Decreto $\mathbf{n}^{\mathbf{0}} \mathbf{8 . 7 5 2}$, de $\mathbf{9}$ de maio de 2016. Dispõe $\quad$ sobre a Política Nacional de Formação dos Profissionais da Educação Básica. Disponível em: <http://www.planalto.gov.br/ccivil_03/_ato2015-2018/2016/decreto/ d8752.htm>. Acessado em: 30/04/2018.

Lei $\mathrm{n}^{\mathbf{0}}$ 13.005, de 25 de junho de 2014. Aprova o Plano Nacional de Educação - PNE e dá outras providências. Disponível em: <http://www. planalto.gov.br/ccivil_03/_ato2011-2014/2014/lei/113005.htm>. Acessado em: 14/04/2018.

. Decreto $\mathrm{n}^{\circ} \mathbf{7 . 4 1 5}$, de 30 de dezembro de 2010. Institui a Política Nacional de Formação dos Profissionais da Educação Básica, dispõe sobre o Programa de Formação Inicial em Serviço dos Profissionais da Educação Básica dos Sistemas de Ensino Público - Profuncionário, e dá outras providências. Disponível em: <http://www.planalto.gov.br/ccivil_03/_ato2007-2010/2010/ decreto/d7415.htm>. Acessado em: 30/04/2018.

. Lei $\mathbf{n}^{\mathbf{0}} \mathbf{1 2 . 0 1 4}$, de 6 de agosto de 2009a. Altera o art. 61 da Lei no 9.394, de 20 de dezembro de 1996, com a finalidade de discriminar as categorias de trabalhadores que se devem considerar profissionais da educação. Disponível em: <http://www.planalto.gov.br/ccivil_03/_ato2007-2010/2009/lei/112014.htm>. Acessado em: 14/04/2018. 
Conselho Nacional de Educação. Câmara de Educação Básica. Resolução

$\mathrm{CNE} / \mathrm{CEB} \mathbf{n}^{\circ}$ 2, de 28 de maio de 2009b. Fixa as Diretrizes Nacionais para os Planos de Carreira e Remuneração dos Profissionais do Magistério da Educação Básica Pública. Disponível em: <http://portal.mec.gov.br/dmdocuments/ resolucao_cne_ceb002_2009.pdf>. Acessado em: 14/04/2018.

- Conselho Nacional de Educação. Câmara de Educação Básica. Resolução CNE/CEB no 2, de 13 de maio de 2016b. Define as Diretrizes Curriculares Nacionais para a Formação Inicial e Continuada em Nível Superior para Funcionários da Educação Básica.

Decreto ${ }^{\circ}$ 6.755, de 29 de janeiro de 2009c. Institui a Política Nacional de Formação de Profissionais do Magistério da Educação Básica, disciplina a atuação da Coordenação de Aperfeiçoamento de Pessoal de Nível Superior CAPES no fomento a programas de formação inicial e continuada, e dá outras providências. Disponível em: <http://www.planalto.gov.br/ccivil_03/_ato20072010/2009/decreto/d6755.htm>. Acessado em: 14/04/2018.

Lei $\mathrm{n}^{\mathrm{o}}$ 11.494, de 20 de junho 2007. Regulamenta o Fundo de Manutenção e Desenvolvimento da Educação Básica e de Valorização dos Profissionais da Educação - FUNDEB, de que trata o art. 60 do Ato das Disposições Constitucionais Transitórias; e dá outras providências. Brasil: Casa Civil, 2007.

Lei $\mathrm{n}^{\circ} 11.738$, de 16 de julho de 2008. Regulamenta a alínea "e" do inciso III do caput do art. 60 do Ato das Disposições Constitucionais Transitórias, para instituir o piso salarial profissional nacional para os profissionais do magistério público da educação básica. Disponível em: <http://www.planalto.gov.br/ ccivil_03/_ato2007-2010/2008/lei/111738.htm>. Acessado em: 14/04/2018.

. Emenda Constitucional $\mathrm{n}^{\circ}$ 53, de 19 de dezembro de 2006. Dá nova redação aos arts. $7^{\circ}, 23,30,206,208,211$ e 212 da Constituição Federal e ao art. 60 do Ato das Disposições Constitucionais Transitórias. Disponível em: <http://www.planalto.gov.br/ccivil_03/constituicao/emendas/emc/emc53. htm>. Acessado em: 14/04/2018. 
. Conselho Nacional de Educação. Câmara de Educação Básica. Resolução $\mathrm{CNE} / \mathrm{CEB} \mathbf{n}^{\circ}$ 5, de 22 de novembro de 2005a. Inclui, nos quadros anexos à Resolução CNE/CEB no 4/99, de 22/12/1999, como 21ª́ Área Profissional, a área de Serviços de Apoio Escolar. Disponível em: < http://portal.mec.gov.br/ setec/arquivos/pdf/legisla_resol05.pdf>. Acessado em: 14/04/2018.

. Conselho Nacional de Educação. Câmara de Educação Básica. Parecer

CNE/CEB 16, de 3 de agosto de 2005b. Proposta de Diretrizes Curriculares Nacionais para a área profissional de Serviços de Apoio Escolar. Disponível em: $<$ http://portal.mec.gov.br/cne/arquivos/pdf/pceb016_05.pdf>. Acessado em: 14/04/2018.

. Lei $\mathrm{n}^{\circ}$ 9.394, de 20 de dezembro de 1996. Estabelece as diretrizes e bases da educação nacional. Disponível em: <http://www.planalto.gov.br/ CCIVIL_03/leis/L9394.htm>. Acessado em: 14/04/2018.

CARREIRA, D.; PINTO, J. M. R. Custo aluno-qualidade inicial: rumo à educação pública de qualidade no Brasil. São Paulo: Global / Campanha Nacional pelo Direito à Educação. 2007.

- Valorização Profissional: piso salarial e carreira. Revista Retratos da Escola, Brasília, v. 10, n. 18, jan.-jun., 2016 a.

. Funcionários da educação: conquistas e desafios da formação e da valorização profissional. Brasilia, 2016b.

. Condições de Trabalho e Saúde dos Profissionais em Educação. Revista Retratos da Escola, Brasília, v. 6, n. 11, jul.-dez., 2012.

CNTE. Funcionário de Escola: identidade e profissionalização. Revista Retratos da Escola, Brasília, v. 3, n. 5, jul.-dez., 2009.

DOURADO, L. F.; MORAES, K. N. Funcionário de escola - Indicadores e desafios. Revista Retratos da Escola, Brasília, v. 3, n. 5, p. 413-436, jul.-dez., 2009.

MONLEVADE, J.A.C. História e construção da identidade - Compromissos e expectativas. Revista Retratos da Escola, Brasília, v. 3, n. 5, p. 339-352, jul.-dez., 2009. 
MONLEVADE, J.A.C. Identidade, carreira e jornada dos profissionais da educação. Cadernos de Educação, Brasília, n. 26, p. 79-97, jan.-jun., 2014.

SILVA, F. Educação básica no Brasil: Políticas e valorização profissional. Revista Retratos da Escola, Brasília, v. 8, n. 14, p. 115-127, jul.-dez., 2014.

VIEIRA, J. D. Valorização dos profissionais: A Carreira e salários. Revista Retratos da Escola, Brasília, v. 8, n. 15, p. 409-426, jul.-dez., 2014.

THIAGO ALVES é Doutor em Administração pela Universidade de São Paulo (FEA/USP) e Professor da Faculdade de Administração, Ciências Contábeis e Ciências Econômicas da Universidade Federal de Goiás (FACE/UFG). E-mail: thiagoalves.edu@gmail.com

LÚCIA MARIA DE ASSIS é Doutora em Educação pela Universidade Federal de Goiás (FE/UFG) e Professora da Faculdade de Educação da UFG. E-mail: luciamariadeassis@gmail.com

ALINE KAZUKO SONOBE é Pedagoga, Mestra em Educação pela Universidade de São Paulo (FFCLRP/USP) e Doutoranda do Programa de Pós-Graduação em Educação da UFPR. E-mail: kazuko.as@gmail.com

MARIANA MOSCHKOVICH ATHAYDE é Pedagoga, bacharel em Jornalismo e Mestranda do Programa de Pós-Graduação em Educação da UFPR. E-mail: mari_athayde@yahoo.com.br 